\title{
Prospects and transformation factors of the institute of logistics providers in the Russian Federation
}

\author{
Tatyana Rusakova ${ }^{1, *}$ and Olga Saychenko ${ }^{1}$ \\ ${ }^{1}$ St. Petersburg State Marine Technical University, Lotsmanskaya 3, 190121 St. Petersburg, Russia
}

\begin{abstract}
The selected topic of the analysis is relevant, since the restoration of the chains disturbed by the COVID-19 pandemic is possible on the basis of digitalization and consolidation of the logistics services market, increasing the innovative mobility of its entities. That is why the purpose of our paper we have chosen to make the analysis of the prospects and problems of the logistics provider development as a special subject of the logistics services market in the terms of contemporary challenges. In the course of working on the paper, the methodology of systems analysis, analysis methods, synthesis and comparative analysis were used. As a result of a comparative analysis of the main 3PL and 4PL providers, the competitive strategic advantages of the latter were revealed. In this regard, the authors have developed a hypothesis: as the time lag of uncertainty increases, the demand for 4PL provider services will grow. The paper considers the structure of the modern competitive environment, in which, according to the authors, the point of growing the domestic 4PL providers and increasing their innovative mobility will be the 3PL providers partnership with startups and their acquisition of new players in specific process areas. At the end of the paper, some barriers are specified that may prevent the implementation of the strategic partnership between the entities of the logistics services market. Conclusions: Formation of the $4 \mathrm{PL}$ providers institution is an advance tool for increasing the logistics industry resistance to stress. The scope of the analysis results can be advisory for logisticians, logistics intermediaries and public authorities.
\end{abstract}

\section{Introduction}

Factors such as globalization and internationalization, increasing competition and orientation to the end user, as well as the development of information and communication technologies and e-commerce have acted as the main drivers of quantitative and qualitative changes in the logistics services market [1-3]. At the turn of the 20th and 21st centuries, the control objects in logistics, along with the flows of material assets, become the accompanying information and financial flows. At the same stage, optimized logistics systems such as OPT (Optimized Production Technologies) have been created and new logistics concepts are being developed, for example, "Supply Chain Management" (SCM) [4-5].

\footnotetext{
* Corresponding author: tanya0310@inbox.ru
} 
According to many authors, qualitative changes have also affected the subject matter of the market. The period of transition from the provision of individual operational services by niche logistics intermediaries (stevedores, warehouse operators, customs brokers, etc.) to the 3PL(Third Party Logistics) proposal by comprehensive service providers or already some 4PL providers (Fourth Party Logistics) of systematic optimization of logistics business processes has started. As a result of all these innovations, we can observe an increase in volume, diversification and digitalization of the services provided by logistics intermediaries from the side of the market offer. With regard to market demand, there is a tendency to gradual integration of logistics intermediaries into the activities of national and international logistics business based on outsourcing technologies, strengthening of cooperation between different stages of value chains in different regions [6-8]. As a result, the modern range of storage-retrieval tasks is increasingly added by managerial and strategic tasks, a stable trend of cooperation between intermediate links (sub-providers) and the development of system logistics providers is being formed. This will entail the development of a qualitatively new subject-object interaction in the market of logistics services based on the use of information and intelligent technologies. To our opinion, more and more preference will be given to the activities of system logistics providers that have an established digital infrastructure and create conditions for effective interaction between market entities [9-11].

New perspectives for activating the integration role of providers are forming a diversified process that takes various forms in the economy. Partly owing to this diversity, the logistics services market has a great adaptive potential. Unfortunately, it showed itself weakly during the crisis of 2014. Thus, in 2014, the average indicator of logistics costs in the world was $11.6 \%$ of GDP; it was about $19 \%$ in our country. During this period, the 2 PL provider services (cargo transportation, forwarding and direct lease of warehouses) prevailed, the share of integrated logistics services (3PL) was $8 \%$ of the turnover of the Russian market of transport and logistics services. A similar indicator for the EU countries is 19\%. The share of logistics outsourcing in the transport and logistics market was $39.3 \%$, and in the world - 55\% [12]. Unfortunately, these data suggested a low adaptation level of the logistics services market in the Russian Federation, which was largely due to the lack of appropriate qualified personnel in the provider institution, as well as distrust of outsourcing and unwillingness to practice it.

To our opinion, one of the main reasons why the logistics services market could not implement its adaptive potential was the fact that many areas of the chain still had not learned how to approach strategically to solving problems, but began to look for ways of their elimination even in the time they appeared. We would like these lessons to be learned by the majority of participants in the logistics services market. Since it is only them who have to find ways to adapt to the more serious changes in the external environment caused by the Covid-19 pandemic. It is understood that the nature of the pandemic impact on the economy, including logistics, is fundamentally different from the nature of the impact of any economic crisis. Firstly, the pandemic factors have a great negative multiplier effect, in the shortest possible time, covering all new economies of the world and sectors of national economies. Secondly, due to the explosive nature of pandemic spread, the time taken by all governments to arrange restrictive measures is greatly reduced, and therefore, the speed and scale of supply chain disturbance increases, the time lag for the search for responses decreases, and thirdly, there is a sharp contraction in consumer and investment demand, etc. Taking into account these particularities of the pandemic impact on logistics, supply chains shall become pragmatic, dynamic, flexible and interconnected by means of the use of modern technology, digitization, routes optimization and enhanced navigation capabilities and the benefits that are put in the processes of commercial collaboration.

This task can be solved with closer and long-term cooperation of enterprises with the integrated 3PL provider and the 4PL system provider. However, to make this possible, there should happen qualitative and quantitative changes in the Russian institute of logistics 
providers itself. This is why the question whether the modern Russian institute of logistics providers is capable of transformation is a relevant issue at present. In this regard, the purpose of our study have been chosen the analysis of the prospects and problems of the logistics provider development as a special subject of the logistics services market in Russian Federation in terms of contemporary challenges.

\section{Materials and Methods}

As a theoretical basis for the study, the authors used the concept of SCM and logistics outsourcing, in which the activities of logistics providers act as a necessary component of the entire theory and practice of logistics.

The logistics provider is company that offers a range of transport, warehousing, distribution and related services to other companies in the supply chain [13]. Their activities are based on the outsourcing model. Outsourcing is using an external supplier for services to a company that cannot provide them for itself, or cannot provide them in an efficient way. However, there are a number of other very compelling reasons to outsource a logistics operation: to enjoy lower supply chain costs, to achieve customer service improvements, to gain access to global capability, to increase flexibility, to benefit from economies of scale. In addition, logistics providers play an important role in strengthening the competitiveness advantage of the entire supply chain [14-15].

In accordance with the generally accepted classification of logistics services, logistics companies can be divided into suppliers of individual services, as well as suppliers providing complex and system services. According to modern designations, these concepts are referred to as 2PL, 3PL, and 4PL providers. The abbreviation PL stands for "party logistics provider", therefore, 1PL "first party logistics provider"- an enterprise that exclusively performs its own logistics tasks. Today, the global trend is the growth of 4PL providers on this market. The term itself was registered in 1996 by the consulting firm Andersen Consulting, currently "Accenture". From their point of view, the fourth-tier logistics provider is a supply chain manager that brings the resources, capacities and technology of its organization with the resources, capacities and technology of another logistics enterprise and manages them in order to offer customers the most complete solution to problems in the supply chain. Other authors have also noted the 4PL provider role as a "solution integrator", or even a "super integrator" [16-18].

The present-day Russia is characterized, on the one hand, by a relatively small percentage of companies cooperating with 3PL on outsourcing terms, and, on the other hand, by the weak development of 4PL-provider mechanisms, as well as the absence of mechanisms and regulations intended for their work. Thus, our country faces the most important and most difficult task - to catch up with the advanced countries in this direction. In Russia, some researchers identify the possibility of a breakthrough transition through the evolutionary order of logistics outsourcing development [19]. Here we are speaking about the possibility of the growth in demand for high-quality management logistics service in the crisis economy caused by the Sovid-19 pandemic. All this can accelerate the transition to the 4PL service in Russia. However the Russian market of logistics services and activities of the logistics providers does not attract particular attention of foreign researchers, as a consequence, the number of academic papers in the international peer reviewed journals, dedicated to this problem, is very low. In this study, we would like to supplement the theoretical analysis of the functioning of the institute of logistics providers with the study of new problems.

We are ready to discuss the following research questions: what challenges has the logistics services market faced during the pandemic; why is the 4PL provider capable of facing these challenges the most successfully of all; what qualitative institutional changes in the structure of the institute of logistics providers can be expected? What directions will they 
go; - what obstacles should be overcome so that the share of the the 4PL provider the innovative economy grew.

In this case, the analysis problems have a multifaceted nature. Taking this into account, to identify the essential characteristics of the 4PL provider and a comprehensive analysis of the current state of the provider in the pandemic conditions, a systematic approach was used, to search for problems and determine the prospects for the 3PL and 4PL provider in the Russian market - methods of analysis and synthesis, methods of comparative analysis. The information base of the study composed legislative acts of the Russian Federation, information and analytical review materials of consulting companies, materials of logistics forums and scientific conferences on logistics and information and computer technologies in business, as well as publications in general economic, industry periodicals on the issues under study.

\section{Results}

With regard to a systematic approach, the logistics services market can be viewed as an open socio-economic system, which is affected by constant changes in the external environment. Until recently, the trajectory of its development and structural transformations were determined by such factors as the formation of global value chains in the process of internationalization of economic ties, changes in the space-temporal characteristics of market interactions in the process of mastering information and communication technologies, changes in the configuration of supply chains of Russian enterprises due to the introduced economic sanctions as well as changes in the configuration of the supply chains of Russian enterprises due to the imposed economic sanctions, the industry structure of the Russian economy, the level of logistics infrastructure, etc. The modern subjective structure of the logistics services market in the Russian Federation is characterized by a weak development of 4PL providers' mechanisms. The share of the Russian market of 3PL providers including about 80 Russian and 40 Western logistics operators was $8.1 \%$ in 2014 . The market share represented by 4 PL-management logistics was $0.6 \%$ [12]. In this case, representatives of transnational logistics providers (DHL, UPS, TNT, Itella Logistics, etc.) prevailed among them, who were the first to enter the Russian market and actively develop it. The recent studies note that the number of logistics providers has noticeably increased, which can no longer be classified as 3PL type, but it is still too early to be classified as 4PL-providers. Among them, the leaders are PEC" "TTG" Rail Continent" "Delko" "DA-TRANS" "FM Logistic" (Russia) "AVTORITET" TEK “ZhelDorEkspeditsiya" "Baikal-Service" "Business lines", etc. We are talking about the so-called combined forms of provider. However, the statistical data should be treated with caution, understanding their conventionality. This is not just because when determining the level of 3PL and 4PL providers logistics services, confusion often arises, which is due to insufficient understanding of the theoretical basis and the lack of accurate information about the parameters of real-life services [17, 20-23].

Currently, the COVID-19 pandemic has become the main factor. Since the COVID-19 pandemic, most logistics enterprises have had disturbances to their logistics hubs and delivery routes due to their location in quarantine areas or complete closure. Many of them suffered due to a significant reduction in consumer demand and its transition to on-line channels, an increase in the time for goods passing through customs, etc. According to M.A. Research based on the consensus forecast of international organizations and banks, in 2020, the growth rates of the Russian market of transport and logistics services in real terms shall enter the area of negative values. In this case, a drop in the volume of traffic in all segments of the transport services market is expected (on the average by $3-4 \%$, with a risk scenario by $8-10 \%$ ) due to narrowing the cargo base, a break in international supply chains, decrease in demand for imports and deterioration in the export situation. A relatively more favorable 
picture in terms of freight turnover is possible only in road transport (a decrease within 1.5\%) as a result of an increase in the distance of domestic transportation (with a drop in international operations by $15 \%$ ), as well as the dynamic development of the e-commerce segment [24].

The further development of the logistics services market seems to us as a process of reaction to new challenges of the external environment by changing the internal structure of the market and the formation of qualitatively new structural relations and interactions. Due to the "fault" of the pandemic, many challenges have arisen for the logistics services market, among which, to our opinion, the following are the main ones:

- ensuring stress resistance. Initially, stress resistance was interpreted as the ability of systems to withstand parameters variability as a result of exposure. Today, wider interpretations of this term have appeared. The definition given by the OECD is closer to the authors. When defining the concept of stress resistance, the organization experts place special emphasis on the ability not only to resist the adverse effects of factors and to recover, but also, gaining new experience, to become stronger. Therefore, "be stress-resistant" means learning to live under uncertainty [25]. This requires building supply chain adaptive the uncertainty based on adherence to fairly rigid principles, among which it is important to note such as network flexibility, digital interaction, tracking the value chain in real time, rapid generation of ideas and, finally, the presence of decentralized teams that independently accept management decisions;

- development of a mechanism for the application and renewal of modern competencies that allow the logistics business to adapt to the growth of complex socioeconomic problems under uncertainty. First of all, "digital readiness" is a serious challenge for the sector, because now the industry shall be ready for the maximum and reasonable use of breakthrough technologies, from automation and robotization to blockchain, cloud technologies and the "physical" Internet. However, in a recent PwC study devoting the Industry 4.0 concept, the share of transport and logistics companies that assess their current level of digitalization as "advanced" was only $28 \%$ [26];

- ensuring self-organization, innovation and competitiveness of the logistics services market, which allows it to build new supply chains within a short time, with a greater focus on national contractors, taking into account the preservation of all restrictive measures and economic slowdown. Now it is important to realize that the quality and timeliness of reaction to unplanned events will depend on the depth of integration of services of all participants in the chain, on non-standard and innovative solutions of each participant. Therefore, the search for innovative mechanisms for self-development and evolution of the logistics system will become a new test for logistics management;

- the need for institutional transformations of the mechanisms of interaction between the state, business, and logistics providers to develop clear game rules under quarantine conditions for the entire business, including representatives of the logistics market. The market needs to simplify logistic formalities, transparency and openness of control and registration procedures. According to the authors, prospects for solving the problem will largely depend on the creation of an effective mechanism for public-private partnership, the ability and desire of all interested parties to coordinate their positions. Not only international logistics forums, but also digital information platforms can be used as a platform for a broad discussion of proposals on harmonization and leveling of the existing differences in applied standards and regulations, elimination of gaps in the regulatory structure in the field of logistics, customs administration. The government should certainly be an active participant in these discussions, making serious commitments to maintain the continuity and strength of supply chains.

To stand against serious challenges, firms need to not only respond quickly to current problems, but also seek answers to questions related to reorganization and relocation 
processes. From the redistribution of competencies between the company and the logistics provider, the choice of areas for transferring activities to other countries being safe from the point of view of COVID-19 spread, and the rethinking of the management model of their supply chains, their stress resistance and strategic advantage will depend in future. To reach this objective, the companies shall use all means, including the competence of logistics providers and outsourcing opportunities.

Under these conditions, the most likely directions of transformation of the institute of logistics providers in the Russian Federation may be:

- the exit from the market of the number of logistics providers who do not have enough business scale, or financial resources to maintain and update their traditional competencies (for example, 2PL provider); the expansion of the professional logistics segment, including through the transition of $2 \mathrm{PL}$ operators to it; the strengthening market position of $3 \mathrm{PL}$ provider, which will be able to update key competencies in accordance with the challenges of the environment;

- the entry of new competitors on the market. Today, new market players, such as IT companies, including start-ups filling information niches and using new business models based on data analysis, the introduction of blockchain and other innovative technologies, are starting to compete with conventional 3PL and 4PL providers. They form on-line platforms for providing transport and logistics services targeted at individual segments of the industry or an individual client, and often become independent platform-aggregators that provide access to various carriers. The use of advanced robotics, unmanned warehouse equipment, automation of many processes in logistics gives them a competitive edge over conventional providers. Already today, they can offer customers a reduction in the number of delays or a reduction in the number of chains disturbance, limiting the influence of the human factor, as well as saving transaction costs associated with the interaction of supply chain management partners, for example, when processing international trade documents. Another advantage is the absence of outdated processes and hierarchical structures;

- the growth in demand for services of the 4PL system provider. The companies' interest in a gradual transition to interaction with a system logistics provider in the period when there is uncertainty in further progression of events may be due to the advantages that the 4PL system provider has over the integrated 3PL provider.

These advantages are:

- a significantly expanded set of services offered by the 4PL system provider. The system provider adds the network analysis and design, consulting, business planning, change management, projects management, coordinating a wide supplier base in many modes and geographic regions, inventory planning and management, monitoring of order fulfillment in supply chains, leasing of logistics capacities, etc. Moreover, the system logistics solutions prepared due to the customer specific production customization are logistics service with high added value;

- the 4PL provider does not have physical assets. Possession of extensive information technology and technology-intensive assets allows it to provide mobility in the interaction of participants in the logistics chain; availability of logistics service by reducing the significance of the geographical factor or time constraints; reliability and continuity of supplies using information technology in relationships with consumers, suppliers and intermediaries;

- the possibility of attracting niche logistics intermediaries, 3PL logistics providers, as well as an IT company to solve the client's problems. As a result, a reliable and well-balanced system is obtained from separate isolated participants, within which the system service provider can organize, integrate and manage individual services in accordance with the customer requests. This interaction is based on an agreement between independent enterprises, which compensates for the blind sides and creates sustainable competitive advantages and contributes to the achievement of synergies [27]. 
It follows from our arguments that, firstly, the functionality of 4PL companies is qualitatively different from the range of 3PL provider services, including strategically important business processes (and not only logistics) for participants in supply chains. Secondly, the 4PL provider creates and then manages the customer's complete supply chain system in real time based on modern information systems and technologies, which ultimately contributes to increasing the value of its business.

The development of the 4PL provider can go of different ways. Our forecast is based on the analysis of the Russian realities. And they are such that, on the one hand, the information technology structure of many $3 \mathrm{PL}$ providers running to the transition to the 4PL level is outdated enough and reflects the needs of the logistics provider itself. Therefore, it does not allow for general management, even if the interfaces for data exchange with customers and subcontractors function well. Accordingly, the 3PL providers are starting to gradually intensify the search for opportunities to introduce new products and services. However, their investments volume in digital startups currently does not exceed $6 \%$ of the total flows of venture capital [26].

On the other hand, the network size and efficiency are increasingly recognized by many logistics companies as the main sources of competitive advantage. In this regard, startups and IT companies also have a chance of becoming the 4PL provider. However, the scientific developments themselves are often of interest to most startup founders. We also note that many of them have no experience in the logistics business. That is why there is always a risk that startups, having received the opportunity to launch and implement innovative projects, will not be further interested in turning the IT startup into an independent logistics provider business.

Thus, if we consider the realities existing on the logistics services market, it seems that the scenario for the 4PL provider development will be the partnership of 3PL providers with startups. Startups will add the service proposal of conventional 3PL providers, especially in the segments of the latest delivery and supporting functions. The following table 1 gives the results of the SWOT- analysis of the model «4PL provider: 3PL+ startups».

Table 1. SWOT- analysis of the model «4PL provider: 3PL + startup» (Source: compiled by author).

\begin{tabular}{|c|c|}
\hline & Weaknesses \\
\hline $\begin{array}{l}\text { - optimization of logistics processes, which } \\
\text { leads to a decrease in transaction and logistics } \\
\text { costs for all participants in the logistics market } \\
- \text { integration of all companies involved in the } \\
\text { supply chain based on digital platforms } \\
- \text { creating an innovative logistics } \\
\text { infrastructure in a short time and at the lowest } \\
\text { cost } \\
- \text { the growth of openness and transparency of } \\
\text { the logistics business } \\
- \text { improvement of logistics competencies } \\
- \text { diversifying and personalizing logistics } \\
\text { services due to the automation of production } \\
\text { and services on-demand } \\
- \text { strengthening the competitive position in } \\
\text { the market }\end{array}$ & $\begin{array}{l}\text { - short life cycle of startups } \\
- \text { difficulties in communication due to } \\
\text { possible incompatibility of the corporate } \\
\text { culture and the innovative culture of startups } \\
\text { and the provider } \\
- \text { unresolved issues in the field of security and } \\
\text { confidentiality of information } \\
- \text { problems of settlement of mutual } \\
\text { settlements, as well as participation in profits } \\
\text { and losses } \\
- \text { a small number of Russian startups } \\
- \text { represented on international information } \\
\text { portals } \\
- \text { takeover of a startup by a logistics provider } \\
\text { - a startup 's disinterest in solving logistics } \\
\text { problems }\end{array}$ \\
\hline & \\
\hline $\begin{array}{l}\text { - special legal regimes ("regulatory } \\
\text { sandboxes") for a wide range of innovations } \\
\text { and technologies } \\
\text { - improving the system of tax measures to } \\
\text { support science and innovation }\end{array}$ & $\begin{array}{l}\text { - single-product economy focused on } \\
\text { pipeline transport } \\
\text { - absence in regulatory legal acts } \\
\text { - clearly defined rights and obligations of } \\
\text { some }\end{array}$ \\
\hline
\end{tabular}




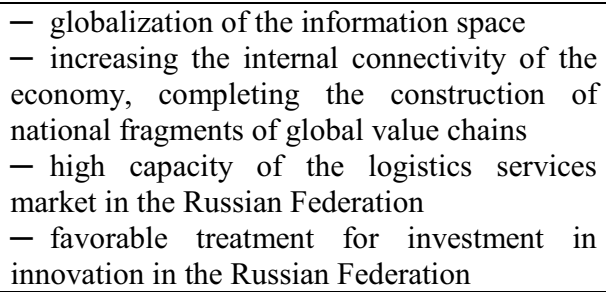

SWOT analysis showed that cooperation with start-ups may be the best strategies of growth are 3PL providers. This will allow them to solve the problems of moving to the 4PL providers faster and at a lower cost than they could do on their own. This cooperation can also be beneficial for startups.

To our opinion, the indicated directions of changes in the institute of logistics providers are the path to breakthrough changes in the logistics services market. Nevertheless, there are many barriers that can "slow down" this process.

The first barrier: the demand for the 4PL provider services, since the logistics services market peculiarity is the fact that a demand forms the need to supply. However, there is no economic interest for companies so far to bind themselves by a long-term contract with the $4 \mathrm{PL}$ provider. It is worth to identify that the main reasons for keeping the conventional mistrust of domestic companies in the conclusion of long- term outsourcing agreements for services with high added value are the lack of operations transparency, concerns about the loss of control over the company's property, concerns about maintaining data security or uncertainty in the level of making and implementing management decisions, etc. In addition, the most domestic 3PL and 4PL providers rely on their own corporate standards and organizational and technological mechanisms built based on the western regulatory foundations and traditions. Currently, in conditions of reorientation to new markets, primarily national markets, this trend can be considered rather a negative driver of development for high-level domestic providers. To overcome the existing stereotypes, to our opinion, the 4PL providers shall not only focus on providing a good portfolio service, but acquire the necessary skill in the field of effective building relationships with their customers based on trust.

The second barrier: the level of 4PL provider's activities informatization. Particular attention should be paid to the availability of the IT platform. In this case, this is not so important if the 4PL itself creates and hosts such a platform, or rather obtains it from an external IT provider and then simply controls the operations. In any case, it is fair to say that the available effective IT platform can have a positive effect on the integration of supply chain partners, especially because it allows for on-line real time data exchange and ensures transaction transparency, and thus increases the level of trust. On the other hand, risks associated with data integrity, data security and confidentiality, etc., are reasonably increasing. Doubts about data security and confidentiality can slow down the integration processes implementation. Difficulties in integrating various information systems may also arise, since the developers of different systems initially made different decisions, assumptions and admissions that conceptually do not fit together. As a result, one may encounter incompatibility of data exchange formats, communication protocols and interfaces or incompatibility of licenses.

The third barrier: the sectoral structure of the national economy. The sectoral, spatial, institutional structure of the economy predetermines, on the one hand, the level and quality of transport and logistics infrastructure development, volume and structure of the transport and logistics services market, and, on the other hand, they form the demand for logistics services of the respective niche.

Thus, currently there are opportunities for growing the professional provider segment. Currently, the specific scenario for the development of this process in practice is difficult to 
predict due to the unprecedented high level of uncertainty regarding the rate and extent of COVID-19 spread. However, it will also depend on the development and implementation of a set of socioeconomic, institutional and legal measures aimed at overcoming barriers. In case of an optimistic scenario, providers of a qualitatively new level will be able to make a significant contribution not only to stress resistance of the logistics industry, but also to the innovative development of the Russian economy.

\section{Discussion}

The scientific novelty of the study lies in theoretical justification of the hypothesis for the possibilities of qualitative transformation of the logistics services market and transition to the supply chains controlled by 4PL provider avoiding the interim stage. Considering the fact that 4PL is the tendency of the next generation of the supply chain in the modern digital economy, we certainly need to shift to this level of logistics with the leaders.

The substantial results that have been gained in the course of our study are the following. First, there have been identified the main challenges from the outside environment, that determine the adequate directions and the speed of the institution of logistics providers transformation.

Second, there have been identified the competitive advantages of the 4PL provider over other participants of the institution of Russian logistics providers in the conditions of the growing uncertainty of the outside environment and digitalization of the national and global economy. Thus we assume that its development will go by the ascending trend because, on the one hand, it has high adaptive potential, and on the other hand it is based upon the fast growth of high technology (for instance, the new generations of mobile networks, breakthrough growth of the data transmission speed, advanced platform technologies, etc.) Then the supply chain can be seen as a net controlled by the 4PL providers.

Third, there have been explored the possible scenarios of strategical behavior of the main participants of the institution of logistics providers, out of which the partnership of the 3PL with startups and their purchase of new players in certain technological directions with their further transformation into the 4PL provider meet the present-day developments in Russian economy. This conclusion is correlated with the results of the SWOT- analysis of the model «4PL provider: 3PL + startup».

Fourth, there have been identified the main obstacles that limit the speed of evolutional transformation in the Russian institution of logistics providers. In order to enter into the new trajectory of development of the logistics services market and to increase its competitive advantage there will be needed consolidation of efforts of all the related participants in the development of socio-economic, institutional, and legal measures aimed at obstacles overcoming. Finally, theoretical and practical significance of the study lies in the knowledge expansion on the matter of the evaluation of prospects for further development of logistics mediation in post-covid economy.

In this paper, most of the issues discussed are polemical, taking into account the novelty of the topic and the emergency situation associated with the pandemic. Therefore, in future, we still have to expect new developments on the qualitative transformation of the provider market, including the issues for identification of its boundaries, detecting the specifics of their interaction in the information space, assessing the prospects for the emergence of 5PL and 6PL provides on the market. 


\section{Conclusions}

Summarizing the above reasoning, we can conclude that the transformation of 3PL logistics into 4PL is not a simple evolutionary process. Its duration cannot be determined now. But one thing is clear that the development of system logistics and the consolidation of the logistics market can lead to the redistribution of service functions to providers that accumulate strategic, informational and other additional modern competencies in logistics. The 3PL and 4PL logistics provider formats will obtain the main growth resource, which have key competencies and widely use information technologies.

Mergers and acquisitions will result in appearing of such providers that are flexible, innovative and have some financial strength. They must be able to provide a full service, taking into account the potential of e-business, coordinating the start and end points of a business operation, ensuring a straight-through transaction. On this evidence, mergers of logistics suppliers representing the new and old economies are most desirable.

\section{References}

1. E. Balashova, E. Palkina, E. Schislyaeva, International Conference on Digital Transformation in Logistics and Infrastructure, ICDTLI 2019. Atlantis Highlights in Computer Sciences 1, 80-85 (2019)

2. S. Maydanova, I. Ilin, Proceedings of the 33rd International Business Information Management Association Conference, IBIMA 2019, Education Excellence and Innovation Management through Vision, 8818-8833 (2020)

3. S. Winkelhaus, E.H. Grosse, International Journal of Production Research 58(1), 18-43 (2020)

4. E. Hofmann, H. Sternberg, H. Chen, A. Pflaum, G. Prockl, International Journal of Physical Distribution \& Logistics Management 49(10), 945-955 (2019)

5. S. Min, Z.G. Zacharia, C.D. Smith, Journal of Business Logistics 40(2), 44-55 (2019)

6. N. Fabbe-Costes, M. Jahre, S. Roussat, International Journal of Productivity and Performance Management 58(1), 71 - 91 (2008)

7. G. Prockl, A. Pflaum, H. Kotzab, International Journal of Physical Distribution \& Logistics Management 42(6), 544-561 (2012)

8. J. Soinio, K. Tanskanen, M. Finne, The International Journal of Logistics Management 23(1), 31-49 (2012)

9. Hosie, P., Sundarakani, B., Tan, A.W.K. and Koźlak, A. Int. J. Logistics Systems and Management 13(3), 287-316 (2012)

10. M. Cichosz, E-mentor 5(77), 73-82 (2018)

11. Program "Digital Economy of the Russian Federation," approved by the Order of the Government of the Russian Federation on July 28, 2017, vol. 1632-r (2017)

12. L. Simonova, TLU market under economic recession: forecast until 2017 (RBK RESEARCH) https://tpprf.ru/common/upload/news/Simonova_RBC_27.01.15.pdf

13. Glossary of MARC Terms, http://ocean.msty.edu.ru/docs/files/20120202 1412-2.pdf

14. C. Martin, Logistics \& Supply Chain Management (FT Press, 2016)

15. F. Fulconis, L. Saglietto, G. Pache, Supply Chain Forum: An International Journal 7(2), 68-70 (2006)

16. S. Mukhopadhyay, R. Setaputra, International Journal of Physical Distribution \& Logistics Management 36(9), 716-729 (2006). 
17. L. Saglietto, Universal Journal of Industrial \& Business Management 1(3), 104-116 (2013)

18. N. Subramanian, A. Gunasekaran, T. Papadopulos, P. Nie, Industrial Management \& Dana Systems 116(7), 1303-1330 (2016)

19. D.S. Bedrin, Economic Sciences 12(169), 76-80 (2018)

20. Z.G. Zacharia, N.R. Sanders, N.W. Nix, Journal of Business Logistics 32(1), 40-54 (2011)

21. D. Egorov, A. Levina, S. Kalyazina et al, Lecture Notes in Networks and Systems 157, 201-209 (2021)

22. K. Selviaridis, M. Spring, The International Journal of Logistics Management 18(1), 125-150 (2007).

23. S. Jharkharia, R. Shankar, Omega International Journal of Management Science, 274289 (2007).

24. L. Simonova, COVID-19 pandemic and the market of transport and logistics services (RBK RESEARCH) https://logistics.ru/upravlenie-logistikoy-i-kompaniey/pandemiyacovid-19-i-rynok-transportno-logisticheskikh-uslug

25. Overview Paper on Resilient Economies and Societies. Meeting of the OECD Council at Ministerial Level (Organisation for Economic Co-operation and Development (OECD), Paris, 2014) https://www.oecd.org/mcm/C-MIN(2014)7-ENG.pdf

26. Paradigm shift: The Future of the Transport and Logistics Sector, PwC Industry Prospects Series, https://www.pwc.ru/ru/assets/pwc-logistics-transformation-rus.pdf

27. M. Dircksen, G. Magnin, Transportation Research Procedia 25, 824-841 (2017) 